\title{
Systemic Administration of a Nerve Growth Factor Conjugate Reverses Age-Related Cognitive Dysfunction and Prevents Cholinergic Neuron Atrophy
}

\author{
Cristina Bäckman, ${ }^{3}$ Gregory M. Rose, ${ }^{2,3,4}$ Barry J. Hoffer,, ${ }^{2,3}$ Michael A. Henry, ${ }^{1}$ Raymond T. Bartus, ${ }^{5}$ \\ Phillip Friden, ${ }^{5}$ and Ann-Charlotte Granholm ${ }^{1,3}$ \\ Departments of ${ }^{1}$ Basic Science and ${ }^{2}$ Pharmacology, and ${ }^{3}$ Neuroscience Training Program, University of Colorado Health \\ Sciences Center, Denver, Colorado 80262, ${ }^{4}$ Medical Research Service, Veterans Affairs Medical Center, Denver, \\ Colorado 80220, and ${ }^{5}$ Alkermes Incorporated, Cambridge, Massachusetts 02139-4136
}

Intraventricular administration of nerve growth factor (NGF) in rats has been shown to reduce age-related atrophy of central cholinergic neurons and the accompanying memory impairment. Intraventricular administration of NGF is necessary because NGF will not cross the blood-brain barrier (BBB). Here we have used a novel carrier system, consisting of NGF covalently linked to an anti-transferrin receptor antibody (OX-26), to transport biologically active NGF across the BBB. In our experiment, aged (24 months old) Fischer 344 rats received intravenous injections of the OX-26-NGF conjugate or a control solution (a mixture of unconjugated OX-26 and NGF) twice weekly for 6 weeks. The OX-26-NGF injections resulted in a significant improvement in spatial learning in previously impaired rats but disrupted the learning ability of previously unimpaired rats. Neuroanatomical analyses showed that OX-26NGF conjugate treatment resulted in a significant increase in cholinergic cell size in the medial septal region of rats initially impaired in spatial learning. These results indicate the potential use of the transferrin receptor antibody delivery system for treatment of CNS disorders with neurotrophic proteins.

Key words: septal nucleus; basal forebrain; neurotrophic factors; nerve growth factor; regeneration; plasticity; acetylcholine; Alzheimer's disease
Nerve growth factor (NGF) is a well characterized neurotrophic factor that is essential for the normal development and function of basal forebrain cholinergic neurons in the CNS (Gnahn et al., 1983; Thoenen and Edgar, 1985). Cholinergic neurons in the medial septal area of the basal forebrain express both low-affinity (p75) and high-affinity (trkA) receptors for NGF (Batchelor et al., 1989; Steininger et al., 1993) and exhibit selective uptake and retrograde transport of labeled NGF from their target areas in the hippocampus and cerebral cortex (Schwab et al., 1979; Seiler and Schwab, 1984). Administration of NGF directly into the brain rescues cholinergic neurons from lesion-induced degeneration and leads to significant increases in the levels and activity of choline acetyltransferase (ChAT), the synthetic enzyme for the neurotransmitter acetylcholine (Mobley et al., 1985; Hefti, 1986; Kromer, 1987; Hartikka and Hefti, 1988; Williams, 1991).

Many studies, in both humans and rodents, suggest a link between age-related cognitive impairments and atrophy or loss of basal forebrain cholinergic neurons (Bartus et al., 1982; Koh et al., 1989; Fischer et al., 1992, Armstrong et al., 1993). Recently it has been shown that intraventricular infusion of NGF can reduce cholinergic neuron atrophy and improve spatial learning or memory retention in aged rats (Fischer et al., 1987, 1991, 1994; Markowska et al., 1994; Scali et al., 1994). The expression of the

Received April 1, 1996; revised June 10, 1996; accepted June 12, 1996.

This work was supported by National Institutes of Health Grants AG12122 to A.C.G., AG10755 to G.M.R., and AG04418 to B.J.H., and by the Veterans Affairs Medical Research Service.

Correspondence should be addressed to Dr. Ann-Charlotte Granholm, Department of Basic Science, Box C286, University of Colorado, Health Sciences Center, 4200 East Ninth Avenue, Denver, CO 80262.

Dr. Friden's present address: Periodontix Inc., Watertown, MA 02172. Copyright (C) 1996 Society for Neuroscience $0270-6474 / 96 / 165437-06 \$ 05.00 / 0$ low-affinity p75 NGF receptors seems to be intimately linked with these processes, because the immunoreactivity for this receptor is decreased in the basal forebrain of aged rodents (Koh and Loy, 1988; Koh et al., 1989; Markram and Segal, 1990, Fischer et al., 1992). Furthermore, it has been demonstrated that there is a correlation between the loss of ChAT or p75 immunoreactivity and decreased spatial memory in aged rats (Koh et al., 1989; Fischer et al., 1992; Armstrong et al., 1993).

The promising results from the animal studies described above have provided a rationale for examining the effects of administration of NGF to patients with senile dementia of the Alzheimer's type (SDAT). In such studies performed to date, positive changes in cerebral blood flow, EEG power spectrum, and nicotinic cholinergic receptor density were observed in two patients receiving NGF directly into the lateral ventricle through a cannula (Olson et al., 1992). Unfortunately, peripherally administered NGF does not pass through the blood-brain barrier (BBB) in physiologically relevant amounts (Kordower et al., 1993; Loy et al., 1994), so that treatment with NGF in SDAT patients has thus far required intracranial surgery.

It has been shown that iron in blood is transported into tissues by means of the blood-borne protein transferrin, which binds to specific receptors on the cell surface (Aisen and Listowsky, 1980). The density of these receptors is increased markedly in CNS capillary endothelial cells (Jeffries et al., 1984). Using this endogenous carrier system, we have demonstrated previously that NGF can be linked covalently to anti-transferrin receptor antibodies and that intravenous injection of the conjugate leads to the transport of biologically active NGF across the BBB (Friden et al., 1993; Granholm et al., 1994; Bäckman et al., 1995). We now present the results of an investigation of the in situ behavioral and 
morphological effects of this conjugate in an animal model of age-related mnemonic impairment.

\section{MATERIALS AND METHODS}

Conjugation of NGF to anti-transferrin receptor antibodies. The antibodygrowth factor conjugation process has been discussed in detail in a previous publication (for review, see Bäckman et al., 1995). Briefly, murine NGF (Harlan Bioproducts for Science, Indianapolis, IN) was radioactively labeled with tritium, and carboxylates on the NGF molecule were activated by the addition of a $60 \mathrm{~m}$ excess of solid 1-ethyl-3(3dimethylaminopropyl)carbodiamide hydrochloride (Pierce Chemical, Rockford, IL). After this step, an appropriate volume of the chemical cross-linker S-(2-thiopyridyl)mercaptopropionic acid hydrazide (PDPH) (Pierce Chemical) was immediately added in $30 \mathrm{~m}$ excess. Sulfhydryl groups were introduced into the OX-26 antibody molecule by incubation with Traut's reagent (2-iminothiolane $\mathrm{HCl}$, Pierce Chemical Company). A $7.5 \mathrm{M}$ excess of PDPH-derivatized NGF was added to the thiolated antibody and incubated overnight at $4^{\circ} \mathrm{C}$. The crude antibody-NGF conjugate was purified on an anti-NGF affinity column. ELISA with plates coated with a rabbit anti-NGF polyclonal antibody was used to verify the composition of the conjugate. (For more details on the conjugation, see Friden et al., 1993; Bäckman et al., 1995.)

Spatial memory testing. All rats were first trained to swim to a hidden platform in a straight alley that was filled with water at $26^{\circ} \mathrm{C}$ (see Fig. 1). The straight swim apparatus was $1 \mathrm{~m}$ long and $15 \mathrm{~cm}$ wide. The rats were given five trials per day for five consecutive days. For each trial, the rats were placed at one end of the tank and were allowed to swim to the escape platform. The rats were allowed to rest for $10 \mathrm{sec}$ on the platform before the next trial. The straight swim apparatus was located in a room adjacent to that in which the spatial learning tests were performed. After straight swim training, spatial learning ability of the animals was determined using techniques modified from Markowska et al. (1993). The rats were required to use information provided by extra-apparatus cues to learn the location of a hidden escape platform $(12 \mathrm{~cm}$ round) located in a circular tank, $1.5 \mathrm{~m}$ in diameter with a wall $0.3 \mathrm{~m}$ high, which was filled with water at $24-25^{\circ} \mathrm{C}$. The top of the platform was $1 \mathrm{~cm}$ under the surface of the water. The tank was located in a room containing numerous sensory cues (e.g., different-colored walls, a table on which the cages of rats were located, an incandescent light) that were maintained in constant locations during the period of behavioral testing. Before the first training trial, each rat was placed on the platform and allowed to remain there for $30 \mathrm{sec}$. Then, with the platform in a consistent location, all animals were given five training trials with an intertrial interval of $\sim 10$ min. A trial consisted of the rat being placed into the water at one of three predetermined start locations; all starting points were used each day, but the order of use varied from day to day. The rat was required to swim for $60 \mathrm{sec}$ or until it located and climbed onto the hidden escape platform. If the platform was not located within $60 \mathrm{sec}$, the rat was hand-guided to the platform. In either case, the animal was allowed to remain on the platform for $15 \mathrm{sec}$ before being removed and returned to its home cage. After the five training trials, a probe trial was given. For the probe trial, the escape platform was retracted and was thus unavailable to the rats for an interval that varied daily between 10 and $40 \mathrm{sec}$. After this time, the platform was raised to its original height to allow the animals to find it. Swim paths and times were recorded using a computerized video tracking system (San Diego Instruments, San Diego, CA). For the probe trial, two measurements were made: (1) the amount of time each rat spent in the quarter of the area of the tank that contained the escape platform and (2) the number of times the rat swam across the place where the platform had been located. The animals received a total of $6 \mathrm{~d}$ of training before the period of drug administration (pretreatment) and $5 \mathrm{~d}$ of training after the period of drug administration (posttreatment). The mean swim time for the last $2 \mathrm{~d}$ of training for each aged rat was compared with the mean for a group of five young adult ( 3 months old) rats. Aged rats that had swim times $>2$ SD above the mean for the young rats (swim times $>22.9 \mathrm{sec}$ ) were considered learning-impaired, whereas the remaining aged rats were considered learning-unimpaired.

Both the learning-impaired and -unimpaired rats were then divided randomly into an experimental group (impaired, $n=6$; unimpaired, $n=$ 5) and a control group (impaired, $n=7$; unimpaired, $n=3$ ). The experimental group received intravenous injections of OX-26-NGF conjugate $(50 \mu \mathrm{g}$ of NGF-equivalent dose/injection) into the tail vein, whereas the control group received intravenous injections of a comixture of unconjugated OX-26 and NGF at the same dose as that given to the experimental group. Tail vein injections were performed twice weekly at the same time for both groups. During the fifth week of treatment, the aged rats were retested in the water maze.

Immunohistochemistry. Rats in the groups initially determined to be learning-impaired, as well as five young adult control rats (3-month-old Fischer 344 rats; Harlan Laboratories, Indianapolis, IN), were anesthetized with chloral hydrate $(300 \mathrm{mg} / \mathrm{kg}$ i.p.), and the brains were fixed by transcardial perfusion with paraformaldehyde $(\mathrm{PF})(2 \%)$ in phosphate buffer (PB) (0.1 M, pH 7.2). Brains were dissected, postfixed in PF overnight, and transferred to $30 \%$ sucrose in PBS $(0.1 \mathrm{M}, \mathrm{pH} 7.2)$ for at least $16 \mathrm{hr}$. Serial cryostat sections ( $30 \mu \mathrm{M}$ thick) were cut through the area of the basal forebrain that contained the medial septal nucleus. Every sixth section through this region was used for immunohistochemical studies. Free-floating sections were rinsed in $0.1 \mathrm{M}$ PBS and treated with $0.3 \% \mathrm{H}_{2} \mathrm{O}_{2}$ to inhibit residual endogenous peroxidase. Sections were then preincubated for $1 \mathrm{hr}$ with normal goat serum (NGS) $(3 \%)$ and bovine serum albumin (BSA) (2\%) in PBS to block background staining. After this, the sections were incubated for $48 \mathrm{hr}$ with the monoclonal antibody 192-IgG directed against the low-affinity p75 NGF receptor (Boehringer Mannheim, Indianapolis, IN) (dilution 1:500 in PBS with Triton X-100, NGS, and BSA; for details, see Bäckman et al., 1995). In the last step, sections were incubated with the ABC Elite substrate, washed in $0.1 \mathrm{M}$ PB (Vector, Burlingame, CA), and reacted with a nickel-enhanced diaminobenzidine reaction. Sections were mounted on glass slides, dehydrated, and coverslipped.

Image analysis. Quantitative measurements of cell size and number were obtained using a scale bar in the microscope in conjunction with a Cohu analog/digital video camera (4990 series), a frame-grabber card, a Macintosh Quadra 450 computer, and the National Institutes of Health "Image" software package, as described in detail elsewhere (Bäckman et al., 1995). The cell diameter of p75-immunoreactive neurons was measured on all neurons in every sixth section through the medial septal nucleus. As a criterion for a cell body, a visible nucleus and two main processes were used (Bäckman et al., 1995). The total number of p75immunoreactive neurons per section in the medial septal nucleus was also obtained, and Abercrombie's formula $(n=n \times t / t+d$; where $n=$ true number of structures, $n=$ number of actual counted structures, $t=$ section thickness, $d=$ mean diameter of counted structures) was applied to calculate the total number of neurons in the septal area. This formula has been used extensively (Abercrombie, 1946; Bowenkamp et al., 1995) in cell count studies to correct for differences in the cell size that could potentially confound accurate determination of cell numbers.

Statistical analysis. The data given represent mean \pm SEM values. For group analysis and statistical comparison of the results in the water maze, a multivariative ANOVA (MANOVA) with Tukey-Kramer a posteriori analysis was used. Image analysis results were analyzed using ordinary ANOVA with Tukey-Kramer a posteriori. The threshold for statistical significance was $p<0.05$.

\section{RESULTS}

\section{Spatial memory testing}

The experimental design is shown in a schematic overview in Figure 1 . The last $2 \mathrm{~d}$ of testing in the initial test series (pretreatment) and the retest after drug treatment (post-treatment) were evaluated, and means were generated for each group of rats. These values were then compared with those found for young adult rats ( 3 months old) in the same task. In contrast to the impaired animals that had received the control solution, the post-treatment performance in the Morris water maze of the aged impaired rats treated with the OX-26-NGF conjugate was improved significantly. This improvement was measurable as both a reduction in the distance swum before the hidden escape platform was found during learning trials (Fig. $2 A)(p<0.001)$ and enhanced performance during memory probe trials, for both the time-in-goal quadrant (Fig. $2 B)(p<0.05)$ and the average number of platform location crossings (Fig. $2 C)(p<0.001)$. Interestingly, conjugate-treated rats that were unimpaired before treatment were significantly worse in the retest, both in terms of the place learning (Fig. $2 A$ ) and in terms of the probe trial measures (Fig. 2B,C). 


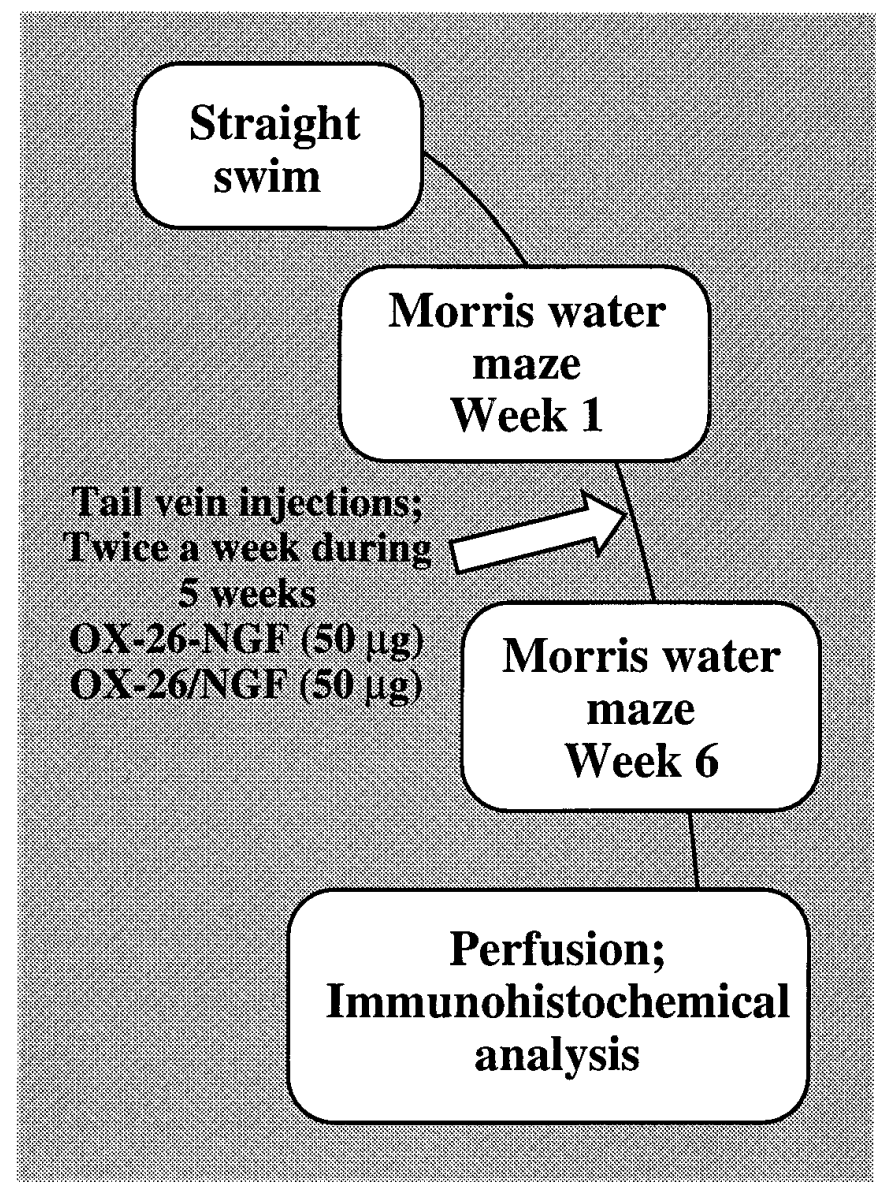

Figure 1. Schematic drawing of the experimental design. The aged rats (24 months old) were first trained to swim and climb onto the escape platform in the straight swim trials (5 consecutive days). Directly after this training period, the rats were pretested in the Morris water maze to discriminate between behaviorally impaired versus unimpaired individuals on the basis of their performance. The rats were then divided randomly into an experimental and a control group, which received tail vein injections twice weekly for 5 weeks. During the last week of injections (week 6 of experiments), the rats were tested again in the water maze to analyze their behavioral response to treatment. All rats were transcardially perfused for immunohistochemical analysis at the end of the testing period.

\section{Immunohistochemistry}

The effects of OX-26-NGF conjugate treatment on the morphology of cholinergic neurons in the medial septal area were investigated. As can be seen in Figure 3, OX-26-NGF treatment resulted in a noticeable increase in p75-immunoreactive nerve fibers in the medial septal nucleus, which was especially prominent in the region occupied by cholinergic cell bodies. The aged impaired animals treated with comixture (Fig. $3 A$ ) showed a very sparse plexus of fibers, as compared with either young adult rats (Fig. 3C) or with OX-26-NGF conjugate-treated impaired animals (Fig. 3B). It also can be seen in Figure 3 that the p75-positive cell bodies in the impaired animals are decreased in size in the aged comixture-treated brains (Fig. $3 A$ ), as compared with the conjugate-treated (Fig. $3 B$ ) or young brains (Fig. $3 C$ ). Image analysis of the cell body size verified a highly significant difference between the aged comixture-treated brains, on one hand, and the young or conjugate-treated aged rats, on the other hand (Fig. 4) $(p<0.001)$. The average cell sizes $( \pm$ SEM $)$ were $107.8 \pm 3.8 \mu \mathrm{m}^{2}$

\section{A. PLACE LEARNING IN AGED F344 RAT EFFECTS OF OX26-NGF PRE-TREATMENT WOA POST-TREATMENT}

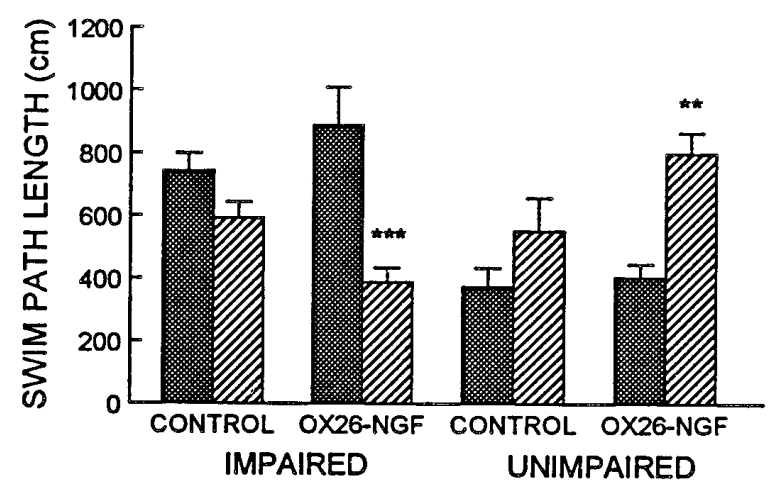

B. TIME IN GOAL QUADRANT

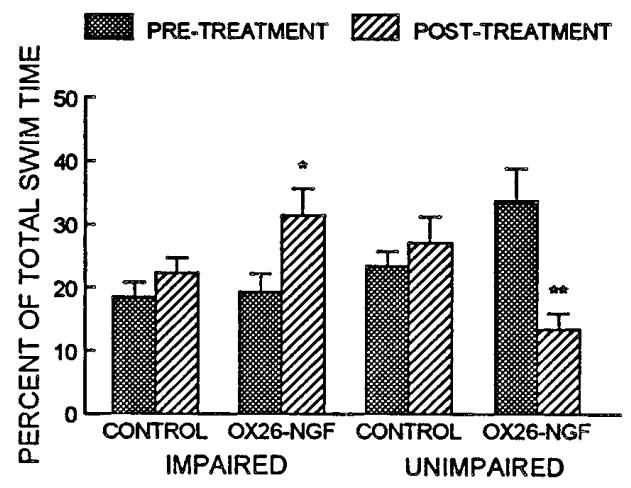

C. platform location crossings

PRE-TREATMENT שIA POST-TREATMENT

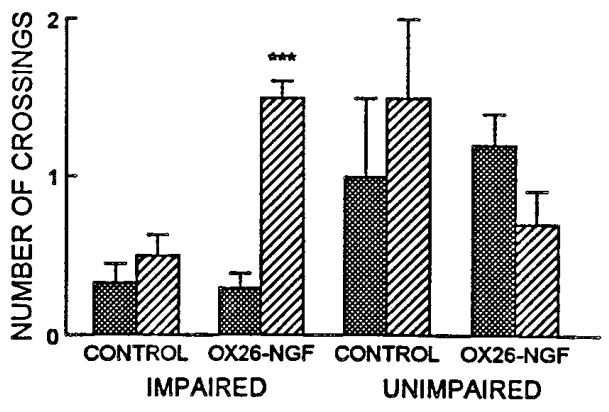

Figure 2. Performance of the rats in the spatial learning task. Data shown are taken from the last two training days for the initial test (PRETREATMENT) and the retest (POST-TREATMENT). A, The learning of initially impaired rats was significantly improved after OX-26-NGF treatment. In contrast, rats that initially had been unimpaired in the task performed significantly worse after OX-26-NGF treatment. $B$, During probe trials, the amount of time spent in the quadrant that had contained the platform was significantly increased for impaired rats and significantly decreased for unimpaired rats when both groups were treated with OX26-NGF. $C$, During probe trials, the number of times the rats crossed the location where the platform had been located was significantly increased for impaired rats treated with OX-26-NGF. ${ }^{*} p<0.05$; ${ }^{* *} p<0.01$; ${ }^{* * *} p<$ 0.001 (MANOVA with Tukey-Kramer a posteriori analysis). 

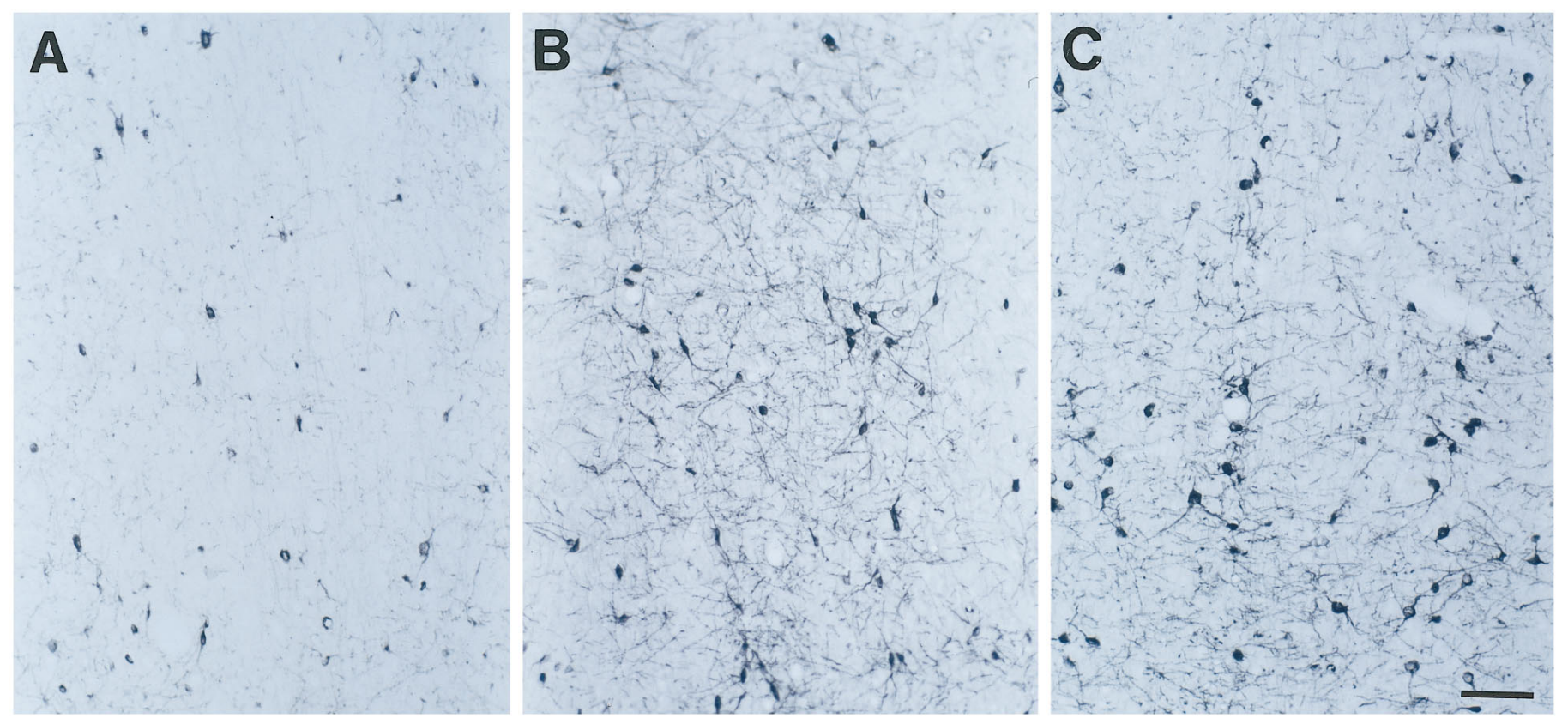

Figure 3. Photomicrographs of the medial portion of the medial septal nucleus. Sections were incubated with a monoclonal antibody specific for the p75 receptor. $A$, Aged rat treated with the OX-26/NGF comixture; $B$, age-matched rat treated with OX-26-NGF conjugate; $C$, young untreated rat ( 3 months old). Note both smaller cell size and decreased number of neurites of p75-immunoreactive neurons in the aged rat treated with comixture $(A)$, as compared with the OX-26-NGF-treated rat in $B$. The conjugate-treated aged animal seemed to have a distribution of p75 immunoreactivity similar to that of the young untreated rat in $C$. A difference in the number and density of stained nerve fibers surrounding the cell bodies is also apparent among the groups. Scale bar (shown in $C$ ), $200 \mu \mathrm{m}$.

in the aged comixture group, $129.6 \pm 3.9 \mu \mathrm{m}^{2}$ in the conjugatetreated group, and $131.2 \pm 3.9 \mu \mathrm{m}^{2}$ in the young control group.

We also counted the total number of p75-stained neurons in the medial septal nucleus and generated mean corrected cell numbers according to the formula described by Abercrombie (1946). The mean $( \pm$ SEM) numbers of p75-immunoreactive neurons in the medial septal nucleus were $1935 \pm 195$ neurons in the young group $(n=5), 1724 \pm 212$ in the aged comixture-treated group $(n=7)$, and $2385 \pm 236$ in the aged group treated with the OX-26-NGF conjugate $(n=6)$. Although there was a trend toward a larger number of $\mathrm{p} 75$-positive neurons in conjugatetreated versus control aged animals, ANOVA indicated no significant difference in cell numbers among the groups.

\section{DISCUSSION}

The present results demonstrate that aged rats, which were shown to be impaired in a spatial learning task, significantly improved their performance after receiving intravenous OX-26-NGF. The improvement in spatial learning ability was coupled with a significant increase in cholinergic cell body size in the basal forebrain. Aged rats that were initially unimpaired in their spatial learning became worse in all aspects of the spatial tasks after administration of OX-26-NGF.

That the aged unimpaired rats performed worse after treatment with OX-26-NGF suggests that an age-related impairment of memory must be present for NGF treatment to be beneficial. This finding correlates well with other studies that showed that intraventricular NGF-treatment in young rats can disrupt spatial learning (Markowska et al., 1994; Chen and Gage, 1995). The neural basis of such an effect remains unclear. It has been suggested, however, that NGF administration to young adult animals can trigger sprouting of intact cholinergic fibers, which leads to undesirable modification of basal forebrain cholinergic system function and results in behavioral impairments (Crutcher and Saffran, 1990; Saffran and Crutcher, 1990). If this hypothesis is correct, enhancing basal forebrain cholinergic tone in aged rats that have reduced function may be beneficial, but a similar enhancement in unimpaired aged rats would have undesirable consequences, such as were observed in this study.

The significant increase in cell body size observed in impaired animals that received OX-26-NGF suggests that nuclear processes have been initiated to restore function in the atrophied aged cholinergic neurons. These data are similar to the findings obtained with intraventricular NGF administration (Fischer et al., 1987, 1991), where the authors found that cell size, but not the cell number, was increased in aged-impaired rats with NGF treatment. Thus, our findings are in agreement with the findings of others with respect to both behavioral and morphological effects of NGF treatment. The significant difference between those studies and our findings is that our study involved noninvasive systemic administration of NGF rather than direct intracranial infusion.

The dose-dependency of cholinergic neuron responsiveness to NGF is difficult to compare among the different studies performed so far. Fischer and collaborators (1987) used a dose of 1 $\mu \mathrm{g} /$ week in their intracranial infusion experiments in aged Sprague-Dawley rats. Because they were using a local application of NGF, the dose is naturally much lower than the dose of 50 $\mu \mathrm{g} /$ injection used here. In a recent study, however, we investigated the dose-response relationship for OX-26-NGF on transplanted cholinergic neurons and found that an intravenous dose equivalent to $10 \mu \mathrm{g}$ of NGF twice monthly was sufficient to produce maximum upregulation of cholinergic parameters, in both developing and aged septal forebrain transplants (Bäckman et al., 1995). Therefore, it is possible that we could lower the dose used in the present study by as much as fivefold and still observe a 


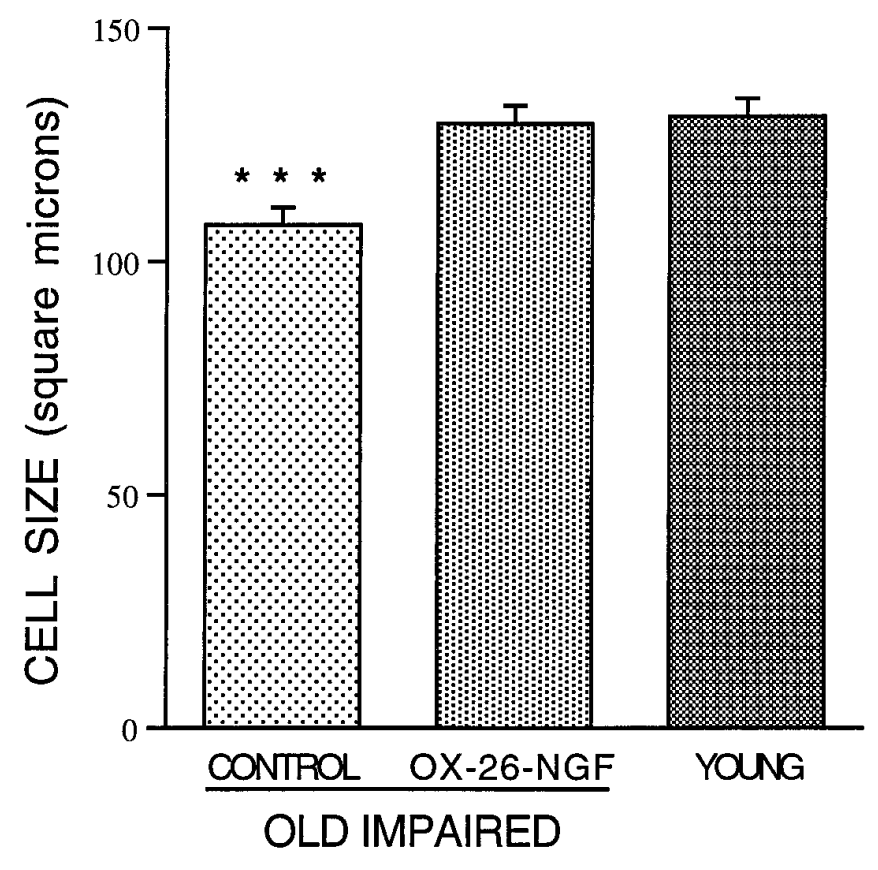

Figure 4. Bar graph showing the average cell size for p75immunoreactive neurons in medial septal nucleus. The average cell size (in $\mu \mathrm{m}^{2}$ ) in the aged comixture-treated rats was significantly smaller than in young normal adult rats. There was no difference, however, between cell sizes observed in young normal adult rats and in aged rats treated with the OX-26-NGF conjugate. $* * * p<0.001$ (aged control versus other groups); ANOVA with Tukey-Kramer a posteriori analysis.

significant effect of this compound on behavioral and morphological parameters in situ. Another aspect of dose-dependency is the question of drug treatment intervals. In our previous study with septal transplants (Bäckman et al., 1995), we administered the OX-26-NGF conjugate twice monthly, whereas in the current study the compound was given twice weekly. To optimize treatment parameters, detailed studies of drug dose and treatment interval are currently underway in our laboratory. It is also important to determine whether there is a temporal window for NGF dependency during aging, such that treatment limited to the beginning of cholinergic cell atrophy could retard or prevent the degeneration process and benefit cholinergic neurons for lengthy time periods. A previous study from our laboratory indicates that this could be the case, because we found that treatment with OX-26-NGF during the first eight postnatal weeks elicited a significant upregulation of cholinergic parameters in septal transplants and that this effect lasted for at least 5 months after cessation of drug treatment (Granholm et al., 1994). Thus, this drug delivery system might be used for studies of long-term effects of trophic factors and also for toxicity studies on the whole animal.

Results obtained so far suggest that treated animals have not manifested any observable negative side effects with long-term administration of the OX-26-NGF conjugate. In our previous studies with intraocular septal transplants, we treated the animals twice monthly from 16 to 26 months of age with OX-26-NGF or unconjugated $\mathrm{OX}-26$ and found no effects on the adrenal gland, an organ that is normally susceptible to NGF treatment (Bäckman et al., 1995). In addition, analysis of blood samples from these animals revealed that there was no significant formation of antibodies against NGF by the host animal, a finding that is important with respect to long-term treatment with trophic factors conjugated to antibodies. Additional studies, however, are needed to determine the effect of conjugate treatment on other NGFresponsive neurons, such as primary afferents, as well as to make detailed measurements of the effects of the conjugate on the sympathetic nervous system, blood pressure, and hormonal balance.

A well documented side-effect of exogenous NGF administration is the induction of hyperalgesia (for review, see Lewin and Mendell, 1993). Experimental studies in animals have demonstrated that peripheral administration of NGF results in both mechanical and thermal hyperalgesia (Lewin and Mendell 1993; Lewin et al., 1994), whereas systemic administration (single intravenous or subcutaneous injection) of NGF in normal human subjects resulted in mild to moderate muscle pain and hyperalgesia (Petty el al., 1994). Thus, although the results of the present study are promising for the future treatment of SDAT with an anti-transferrin NGF conjugate, a possible complication could involve hyperalgesia and pain. Additional studies will be necessary to investigate the possible development of hyperalgesia and/or increased nocicepcion in experimental animals that have received intravenous injections of the OX-26-NGF conjugate.

The results presented here have broad implications. This study confirms previous work by other authors indicating that NGF administration can attenuate mnemonic dysfunction in the aged rodent and that this effect on memory is related to an effect on cholinergic neurons in the basal forebrain (Fischer et al., 1991). More generally, this work demonstrates that progress has been made toward the difficult task of delivering large proteins into the brain. This delivery system could also be used for administration of other neurotrophic factors or specific target proteins for treatment of various CNS disorders.

Note added in proof: Lindner et al. (Cell Transplantation 5:205$223,1996)$ recently observed behavioral improvements and increases in basal forebrain cholinergic neurons in aged rats after i.c.v. implantation of encapsulated hamster kidney cells modified to secrete NGF. The dose of NGF in this work was $\sim 10 \mathrm{ng} / \mathrm{day}$. This dose did not alter nocicepcion as assessed by hot-plate test.

\section{REFERENCES}

Abercrombie M (1946) Estimation of nuclear population from microtome sections. Anat Rec 94:239-247.

Aisen P, Listowsky I (1980) Iron transport and storage proteins. Annu Rev Biochem 49:357-393.

Armstrong DM, Sheffield R, Buzsaki G, Chen KS, Hersh LB, Nearing BG, Gage FH (1993) Morphologic alterations of choline acetyltransferasepositive neurons in the basal forebrain of aged behaviorally characterized Fischer 344 rats. Neurobiol Aging 14:457-470.

Bäckman C, Biddle PT, Ebendal T, Friden PM, Gerhardt GA, Henry MA, Mackerlova L, Söderström S, Strömberg I, Walus L, Hoffer BJ, Granholm A-C (1995) Effects of transferrin receptor antibody-NGF conjugate on young and aged septal transplants in oculo. Exp Neurol 132:1-15.

Bartus RT, Dean RL, Beer B, Lippa AS (1982) The cholinergic hypothesis of geriatric memory dysfunction. Science 217:408-417.

Batchelor PE, Armstrong DM, SN Baker SN, Gage FH (1989) Nerve growth factor receptor and choline acetyltransferase colocalization in neurons within the basal forebrain: response to fimbria fornix transection. J Comp Neurol 284:187-204.

Bowenkamp KE, Hoffman AF, Gerhardt GA, Henry MA, Biddle PT, Hoffer BJ, Granholm A-C (1995) Glial cell line-derived neurotrophic factor supports survival of injured midbrain dopaminergic neurons. J Comp Neurol 355:479-489.

Chen KS, Gage FH (1995) Somatic gene transfer of NGF to the aged brain: behavioral and morphological amelioration. $\mathrm{J}$ Neurosci 15:2819-2825.

Crutcher KA, Saffran BN (1990) Trophomorphism: a unifying hypothesis to explain neuronal rearrangements. Soc Neurosci Abstr 16:993. 
Fischer W, Wictorin K, Björklund A, Williams LR, Varon S, Gage FH (1987) Amelioration of cholinergic neuron atrophy and spatial memory impairment in aged rats by NGF. Nature 329:53-61.

Fischer W, Björklund A, Chen K, Gage FH (1991) NGF improves spatial memory in aged rodents as a function of age. J Neurosci 11:1889-1906.

Fischer W, Chen KS, Gage FH, Björklund A (1992) Progressive decline in spatial learning and integrity of forebrain cholinergic neurons in rats during aging. Neurobiol Aging 13:9-23.

Fischer W, Sirevaag A, Wiegand SJ, Lindsay RM, Björklund A (1994) Reversal of spatial memory impairments in aged rats by nerve growth factor and neurotrophins 3 and $4 / 5$ but not by brain-derived neurotrophic factor. Proc Natl Acad Sci USA 91:8607-8611.

Friden PM, Walus LR, Watson P, Doctrow SR, Kozarich JW, Bäckman C, Bergman H, Hoffer B, Bloom F, Granholm A-C (1993) Blood-brain barrier penetration and in vivo activity of an NGF conjugate. Science 259:373-377.

Gnahn H, Hefti F, Heumann R, Schwab ME, Thoenen H (1983) NGFmediated increase of choline acetyltransferase (ChAT) in the neonatal forebrain; evidence for a physiological role of NGF in the brain? Dev Brain Res 9:45-52.

Granholm A-C, Bäckman C, Bloom F, Ebendal T, Gerhardt GA, Hoffer B, Mackerlova L, Olson L, Söderström S, Walus LR, Friden PM (1994) NGF and anti-transferrin receptor antibody conjugate: short and long term effects on survival of cholinergic neurons in intraocular septal transplants. J Pharmacol Exp Ther 268:448-459.

Hartikka J, Hefti F (1988) Comparison of nerve growth factor effects on development of septum, striatum and nucleus basalis cholinergic neurons in vitro. J Neurosci Res 21:352-364.

Hefti F (1986) Nerve growth factor promotes survival of septal cholinergic neurons after fimbrial transection. J Neurosci 6:2155-2166.

Jeffries WA, Brandon MR, Hunt SV, Williams AF, Gatter KC, Mason DY (1984) Transferrin receptors on endothelium of brain capillaries. Nature 312:162-163.

Koh S, Loy R (1988) Age-related loss of NGF sensitivity in rat basal forebrain neurons. Brain Res 440:396-401.

Koh S, Chang P, Collier TJ, Loy R (1989) Loss of NGF receptor immunoreactivity in basal forebrain neurons of aged rats: correlation with spatial memory impairment. Brain Res 498:397-404.

Kordower JH, Mufson EJ, Granholm A-C, Hoffer B, Friden PM (1993) Delivery of trophic factors to the primate brain. Exp Neurol 124:21-30.

Kromer LF (1987) Nerve growth factor treatment after brain injury prevents neuronal death. Science 235:214-216.

Lewin GR, Mendell LM (1993) Nerve growth factor and nociception. Trends Neurosci 16:353-359.

Lewin GR, Rueff A, Mendell LM (1994) Peripheral and central mechanisms of NGF-induced hyperalgesia. Eur J Neurosci 6:1903-1912.
Loy R, Taglialatela G, Angelucci L, Heyer D, Perez-Polo R (1994) Regional uptake of blood-borne nerve growth factor. J Neurosci Res 39:339-346.

Markowska AL, Long JM, Johnson CT, Olton DS (1993) Variableinterval probe test as a tool for repeated measurements of spatial memory in the water maze. Behav Neurosci 107:627-632.

Markowska AL, Koliastos VE, Breckler SJ, Price DL, Olton DS (1994) Human nerve growth factor improves spatial memory in aged but not in young rats. J Neurosci 14:4815-4825.

Markram H, Segal M (1990) Regional changes in NGF receptor immunohistochemical labeling in the septum of the aged rat. Neurobiol Aging 11:481-484

Mobley WC, Rutkowski JL, Tennekon GI, Buchanan K, Johnston MV (1985) Choline acetyltransferase in striatum of neonatal rats increased by nerve growth factor. Science 229:284-287.

Olson L, Nordberg A, Von Holst H, Bäckman L, Ebendal T, Alafuzoff I, Amberla K, Hartvig P, Herlitz A, Lilja A, Lundqvist H, Långström B, Meyerson B, Persson A, Viitanen M, Winblad B, Seiger A (1992) Nerve growth factor affects ${ }^{11} \mathrm{C}$-nicotine binding, blood flow, EEG, and verbal episodic memory in an Alzheimer patient. J Neural Transm 4:79-95.

Petty BG, Cornblath DR, Adornato BT, Chaudhry V, Flexner C, Wachsman M, Sinicropi D, Burton LE, Peroutka J (1994) The effects of systemically administered recombinant human nerve growth factor in healthy human subjects. Ann Neurol 36:244-246.

Saffran BN, Crutcher KA (1990) NGF-induced remodeling of mature uninjured axons collaterals. Brain Res 525:11-20.

Scali C, Casamenti F, Pazzagli M, Bartolini L, Pepeu G (1994) Nerve growth factor increases extracellular acetylcholine levels in the parietal cortex and hippocampus of aged rats and restores object recognition. Neurosci Lett 170:117-120.

Schwab ME, Otten U, Agid Y, Thoenen H (1979) Nerve growth factor (NGF) in the rat CNS: absence of specific retrograde axonal transport and tyrosine hydroxylase induction in locus coeruleus and substantia nigra. Brain Res 168:473-483.

Seiler M, Schwab ME (1984) Specific retrograde transport of nerve growth factor receptor (NGF) from neocortex to nucleus basalis in the rat. Brain Res 300:33-39 .

Steininger TL, Wainer BH, Klein R, Barbacid M, Palfrey HC (1993) High affinity nerve growth factor receptor (Trk) immunoreactivity is localized in cholinergic neurons of the basal forebrain and striatum in the adult brain. Brain Res 612:330-335.

Thoenen H, Edgar D (1985) Neurotrophic factors. Science 229:238-248.

Williams LR (1991) Exogenous nerve growth factor stimulates choline acetyltransferase activity in aging Fischer 344 male rats. Neurobiol Aging 12:39-46. 